\title{
The Health-Related Quality of Life of South African Paediatric In-patients with Cancer
}

\author{
*S'thembiso C. Tembe; BOT (UKZN), PG Dip Pal Med (UCT) MSc OT (Wits). \\ http://orcid.org/0000-0002-7697-6363 \\ Chief Occupational Therapist, Eastern Cape Department of Education. Postgraduate student, Department of Occupational \\ Therapy, School of Therapeutic Sciences, Faculty of Health Sciences, University of Witwatersrand.
}

\section{Lindsay Koch; BSc OT (UFS), MSc OT (Wits). http://orcid.org/0000-0002-7440-233 I}

Lecturer, Department of Occupational Therapy, School of Therapeutic Sciences, Faculty of Health Sciences, University of Witwatersrand.

Denise Franzsen; BSc OT (Wits); MSc OT (Wits); DHT (UP); PhD (Wits). http://orcid.org/0000-000 I-8295-6329 Sessional Senior Lecturer, Department of Occupational Therapy, School of Therapeutic Sciences, Faculty of Health Sciences, University of the Witwatersrand.

\author{
Patricia de Witt; Nat. Dip. (OT) (Pret), MSc OT (Wits) PhD (Wits). \\ http://orcid.org/0000-0003-36 I 2-0920 \\ Sessional Adjunct Professor, Department of Occupational Therapy, School of Therapeutic Sciences, Faculty of Health Sciences, \\ University of Witwatersrand.
}

Introduction: In the South African public health system, children with cancer are admitted to specialised oncology units for the duration of their treatment. These units therefore become the children's temporary living environment for varying periods of time, which may disrupt their participation in daily activities and consequently their health-related quality of life (HRQoL).

Aim: The purpose of the study was to determine the HRQoL of children admitted with cancer from both their own and their parents' perspective.

Methodology: A quantitative, descriptive, cross-sectional study was conducted at a tertiary hospital in Gauteng with a specialist oncology unit. Structured interviews were conducted with the children aged 8-I 2 years using the PedsQL ${ }^{T M}$ Generic Core Scale (4.0) and Cancer Module (3.0). The parent's perspective was explored using the Parents proxy forms of both instruments.

Results: Twenty-five children and their parents participated in the study. Most children in the sample were males with Leukaemia. All children and parents reported the children's functioning at an intermediate level which suggests that these children may be at risk for $H R Q o L$ deficits. Children's HRQoL was impacted by psychosocial functioning and change in schooling on the PedsQL ${ }^{T M}$ Generic Core Scale (4.0), while parents felt physical functioning played a greater role in determining the child's HRQoL. On the PedsQL $L^{T M}$ Cancer Module (3.0) both the children and parents felt that 'procedural anxiety' had an effect, although from the parents' perspective, 'worry' accounted for the greatest deficits in their children's HRQoL.

Conclusion: This study indicates that occupational disruption is experienced by children during the long-term treatment of cancer. It is suggested that occupational therapists use available instruments to monitor and provide support for the effect of an impaired $H R Q$ oL.

Key words: Health-related quality of life, Cancer, Children, Parental perspective, PedsQL ${ }^{\mathrm{TM}}$ Generic Core Scale (4.0) and Cancer Module (3.0).

\section{INTRODUCTION}

Internationally, cancer is considered rare in childhood ${ }^{1,2}$ although in South Africa, a middle-income country, research reports higher mortality rates from cancer than the global average ${ }^{3}$. This higher mortality rate of children with cancer in South Africa is linked to children often presenting at a later stage of the disease and with more severe illness due to a lack of or a late diagnosis ${ }^{3}$. Late diagnosis has also been attributed to overburdened oncology services, poor cancer awareness at the primary healthcare level, as well as widespread health service delivery challenges ${ }^{3}$. Many children with advanced cancer therefore require specialised oncology care. These specialised services in the public healthcare sector (where $85 \%$ of the population access care) are only available in large metropolitan areas where children with cancer are referred for inpatient treatment ${ }^{2}$. The oncology unit at the academic hospital in Pretoria, Gauteng, is one such centre which provides services to children from both the local and distant provinces of Mpumalanga, Limpopo, and North-West. Hospitalisation in the paediatric oncology unit sometimes exceeds six months and is often far from the child's home and support systems. During the child's hospitalisation, 
over and above concerns about the illness, treatment and short- or longer-term outcomes, the child faces disruption in participation in meaningful everyday activities, contact with family and friends as well as schooling 4,5,6 all of which could affect their health-related quality of life (HRQoL) ${ }^{6}$.

Health-related quality of life has become an important measure of cancer outcomes for the multidisciplinary team of professionals including occupational therapists, when providing support in dealing with the impact of the condition ${ }^{7}$. The change in occupational engagement as a result of treatment, side effects and long term consequences, negatively affect activity participation, which is of particular concern to occupational therapists ${ }^{8,9}$. Understanding the perspective of the child with cancer and that of their parents may assist the occupational therapist to provide person-centred intervention to support overall engagement in activities, participation, and wellbeing ${ }^{10}$. Functional limitations in terms of physical, social, psychosocial and emotional functioning as well as participation in meaningful everyday activities (including education), can then be addressed ${ }^{11,12}$. Assisting with organising daily routines, energy conservation techniques, and setting realistic expectations can also enhance HRQoL ${ }^{13}$. A scoping review by Wallis, Meredith and Stanley ${ }^{7}$ in 2020 identified the need to define the nature and scope of the profession in cancer care. They reported limited evidence for occupational therapy outcomes in terms of improved occupational engagement and quality of life ${ }^{7}$.

In spite of challenges faced by children with cancer in South Africa, the provision of occupational therapy in public sector oncology settings has been lacking, Furthermore, no literature on either HRQoL or occupational therapy to address occupational performance deficits during the hospitalisation period ${ }^{14}$ could be found at the time of this study, in South Africa. This study therefore aimed to explore the HRQoL in South African children aged 8-12 years during admissions to a public service hospital for treatment of cancer from the children's and the parents' perspectives.

\section{Literature Review}

In $70-90 \%$ of childhood cancer cases the causes are unknown, with a family history, genetics and known environmental exposures and exogenous factors accounting for less than $5-10 \%$ of cases ${ }^{15}$. Internationally, acute lymphoblastic leukaemia is the most common type of paediatric cancer, followed by acute myeloid leukaemia (75\%). Malignant spinal cord and brain tumours account for about $21 \%$, and lymphomas for $4 \%$ of childhood cancer ${ }^{15}$. This reported incidence of the five most common childhood cancers also reflects the situation in South Africa ${ }^{16}$. Although survival rates may differ according to gender or age groups, in South Africa mortality also depends on ethnic group, particularly for children who present with nephroblastoma and retinoblastoma ${ }^{16}$.

The individualisation or personalisation of cancer management or treatment at the time of diagnosis or relapse is based on chromosomal risk features, the pattern of gene expression, clinical condition, biological characteristics, response to preliminary treatments, and demographic location of the child ${ }^{17,18}$. Cancer management differs with each intervention phase. During the induction phase, high doses of chemotherapy to eliminate as many cancer cells as possible, are used. For advanced cancers, this initial treatment improves the effectiveness of radiotherapy and before surgery, where necessary ${ }^{19}$. Consolidation treatment begins when the child goes into remission and may involve high-dose chemotherapy to eliminate remaining cancer cells. During the maintenance phase, additional chemotherapy may continue for up to two years to prevent recurrence and to effect a cure ${ }^{20,21}$

These treatments may require long periods of hospitalisation ${ }^{22}$ resulting in significantly reduced participation in meaningful and valued activities when compared to healthy children in play, ADLs, education and social participation ${ }^{23}$. Mohammadi, Mehraban and Damavandi ${ }^{23}$ found that these children had less active engagement and experienced less enjoyment in their activities. This impacts negatively on the occupational needs of the children and this temporary disturbance of their occupational performance can be aligned with occupational disruption ${ }^{24}$. Occupational therapists need to consider this occupational disruption from the perspective of the hospital environment, the illness and the cancer treatment, as well as how the disruption may singly or collectively affect the HRQoL of these children ${ }^{4,25}$.

\section{The Health-Related Quality of Life and Childhood Cancer}

Health-related quality of life is a multidimensional construct based on the overall self-perceived physical and mental health status of individuals, focusing primarily on the impact of the illness, different treatments and the effect on usual activities, such as activities of daily living, schooling/education or leisure ${ }^{26,27}$. Research has confirmed that conceptually, HRQOL should include not only physical and emotional dimensions, but also psychological, social role functioning as well as general well-being ${ }^{28}$. Because cancer can impact on functioning in all areas of life, HRQoL has become a frequently-used outcome in clinical studies, including in occupational therapy, for patients of all ages with cancer ${ }^{12}$.

For the assessment of HRQoL in children with cancer, the PedsQL ${ }^{T M}$ has been validated and is widely used clinically and in research ${ }^{29}$. The PedsQL ${ }^{T M} 4.0$ Generic Core Scales include core physical, mental, and social health dimensions, as well as role functioning. There are child report forms for children of various ages including one for middle childhood (8-12 years). A parent proxy form is also available to assess the parent's perceptions of the child's HRQoL ${ }^{29,30}$. Although children from the age of 8 years can report on their own quality of life, the assessment of HRQoL for younger children and those with cancer is usually done by the child's parents ${ }^{29}$. Structured interviews are commonly used with children with cancer to determine their HRQoL while proxy self-reports are completed by the parents on the child's HRQoL. The reports by the children and parents have however indicated some differences or imperfect concordance ${ }^{30,31}$. Since HRQoL also considers how the child is dealing with the condition and its treatment consequences when in hospital ${ }^{29}$, Peds $\mathrm{QL}^{\mathrm{TM}}$ disease specific modules (which include a cancer module) have been designed for integration with the PedsQLTM generic scale ${ }^{29}$. This module also includes a child report and parent proxy self-report. The cancer module assesses the effects of treatment for cancer including side effects such as nausea and pain, physical appearance, as well as treatment and procedural anxiety, worry and communication with health services ${ }^{29}$.

Literature indicates that generic function related to HRQoL, as well as specific components related to cancer in children are impacted. Sung et al. ${ }^{32}$ found HRQoL in children with brain tumours to be two standard deviations below the norm when compared to healthy children for physical, emotional, social, and school functions.. These limitations result in interruptions in daily routines and dysfunction in occupational performance, which should be addressed by occupational therapy intervention ${ }^{33}$. This includes reduced physical functioning affected by fatigue and weakness due 
to reduced daily energy and lower levels of physical activity often associated with side-effects of treatment and pain ${ }^{34}$. There is also an increased risk of deficits in cognitive functioning in terms of memory, visual perception and executive function ${ }^{35}$. Emotional and social functioning commonly noted in these children are anxiety, fear and depression, and behavioural difficulties associated with changes in self-esteem and self-image due to deformities ${ }^{8,23,36}$. Signs of developmental delay, sleep disorders, eating disorders, dependency on caregivers have been noted in children admitted to oncology wards ${ }^{37}$. Adolescents hospitalised for cancer treatment stressed the need for educational activities, and reported that the lack of a standardised routine and relationships with peers affected their quality of life ${ }^{4}$, which in South Africa can be further affected by multiple hospital admissions ${ }^{22}$.

However, factors impacting HRQoL in children with cancer receiving treatment appear to be context specific. Studies in Japan ${ }^{38}$ and $\mathrm{Brazi}^{39}$ report good $\mathrm{HRQ}$ oL related to pain and hurt and treatment anxiety while a study in China ${ }^{40}$ indicated all factors assessed on the PedsQL ${ }^{T M}$ 3.0 Cancer module result in a decreased HRQoL for these children. Specific occupational therapy for the effects of treatment in hospitalised children with cancer, such as procedural and treatment anxiety, cognitive problems pain and fatigue has also been shown to be effective ${ }^{23}$.

\section{METHOD}

\section{Study design}

A quantitative, descriptive, cross-sectional study was conducted.

\section{Population and sampling}

The primary participants in the study were children aged 8- 12 years, who had a confirmed diagnosis of cancer and were in-patients in the oncology unit of a public healthcare tertiary hospital in Gauteng. Based on the average of 25 children admitted to the unit per month over a six-month data collection period, the population was estimated to be 150 children. A sample of 45 participants was therefore needed to represent this population, with a confidence interval of $95 \%$ and a $10 \%$ margin of error ${ }^{41}$.

School-going children aged 8-1 2 years were selected for the study since they could understand verbal instructions and participate in a face-to-face structured interview. They had also all experienced the effects of the illness as well as the side-effects of treatment and could report on the impact upon their HRQoL. Children in this age group are reported to understand the concept of activities related to their occupational performance areas of play, school, socialisation, and personal management ${ }^{42}$. Hence it was anticipated that they would be able to provide information on how these specific occupations had changed since they became ill. The secondary participants were the parents who accompanied their child and stayed in the hospital lodge.

Convenience sampling was used to recruit eligible participants within the paediatric oncology unit. Children between 8 and 12 years old were included in the study if they had a diagnosis of cancer made more than one month previously and had completed the induction phase of treatment at the tertiary hospital. Children were excluded from the study if they were admitted without a parent; were diagnosed with developmental disorders or visual impairments; and if the parent had not provided informed consent or the child had not given assent.

\section{Research instruments}

Two data collection tools were used in this study. Firstly, the Paediatric Quality of Life (PedsQL'M ) modules: Generic Core Scale (4.0) and Cancer (3.0) in the form of the child report children participants were used. Secondly, the parent participants completed the proxy PedsQL ${ }^{T M}$ modules: Generic Core Scale (4.0) and Cancer Module (3.0).

\section{The PedsQLTM 4.0 Generic Core Scale}

The PedsQL 4 TM Generic Core Scales was originally designed to measure core functional components of HRQoL. The scale has 23 questions which cover four domains: Physical, Emotional, Social functioning and Schooling. The PedsQL ${ }^{T M} 4.0$ Generic Core Scales are scored using a Total Score (23 items), a Physical Health Summary Score (8 items) and a Psychosocial Health Summary Score)

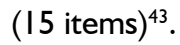

The child self-report form for children between 8-12 years can be completed as a structured interview. The parent proxy self-report for this scale covers the same questions. The psychometric properties of the assessment have been evaluated in several international studies to establish validity and reliability and has been translated into 60 languages ${ }^{40}$. No published studies using this assessment in South Africa were found.

\section{PedsQLTM Cancer Module (3.0)}

The PedsQL'M Cancer Module (3.0) is designed to measure the impact of symptoms and treatment of cancer experienced by the child in relation to the HRQoL. PedsQL ${ }^{\mathrm{TM}}$ Cancer module consists of 27 items which are divided into eight subscales pain and hurt (2), nausea (5), procedural anxiety (3), treatment anxiety (3), worry (3), cognitive problems (5), perceived physical appearance (3), and communication $(3)^{29}$. The module is a self-report questionnaire used with children between 8 and 12 years which can be also be completed in a structured interview.

The parent proxy self-report form assesses the same domains. The Cancer Module was validated on an oncology sample, which included various cancers. The psychometric properties of the assessment have been evaluated in several studies to establish validity and reliability in different contexts and its relevance to other populations ${ }^{29,38-40}$. However, no validation studies have been done on children in South Africa.

\section{Scoring}

In both the PedsQL ${ }^{\mathrm{TM}}$ modules: Generic Core Scale (4.0) and Cancer (3.0) item scoring uses a 5-point Likert scale from zero (never) to four (almost always) and a domain-specific and total score is calculated from the corresponding questions, ranging from 0 to 100 . A higher score indicates better HRQoL. If more than $50 \%$ of the scores for a domain are missing, the scores should not be included. The authors of the PedsQL $\mathrm{L}^{\mathrm{TM}} 4.0$ suggest cut-off point scores at -ISD below the population mean to indicate at-risk status for impaired HRQoL for both child self-report and parent proxy-report. These scores are reported for the total child self-report at 69.7 and at 65.4 for the total parent proxy-report score ${ }^{43}$. No cut-off scores are available for the PedsQL ${ }^{T M}$ Cancer (3.0) module. Therefore, the levels of HRQoL used for this study were based on those suggested by Beverung, Varni and Panepinto ${ }^{44}$, where high (scores above 81 ), intermediate (scores between $6 \mathrm{I}$ and 80 ) and low (scores of 60 or lower) functioning was based on the number "never" or "almost never" responses on the PedsQL ${ }^{T M}$ modules for children with sickle cell disease. Although the authors used a difference module of the 
Table I Participants' demographics $(n=25)$

\begin{tabular}{|c|c|c|c|c|c|c|c|}
\hline \multicolumn{4}{|l|}{ Child demographics } & \multicolumn{4}{|c|}{ Parents demographics } \\
\hline & & Mean & \multirow{3}{*}{\begin{tabular}{|l|} 
SD \\
1.84 \\
$(\%)$ \\
\end{tabular}} & & Range & Mean & SD \\
\hline \multirow[t]{7}{*}{ Age } & Years. Months & \multirow{2}{*}{\begin{tabular}{|l|}
10.32 \\
(n) \\
\end{tabular}} & & \multirow[t]{3}{*}{ Age } & \multicolumn{3}{|c|}{ Years } \\
\hline & & & & & $26-43$ & 39 & 6.86 \\
\hline & $8.0-8.11$ & 8 & 32 & & & (n) & (\%) \\
\hline & $9.0-9.11$ & 2 & 8 & Gender & Females & 20 & 80 \\
\hline & $10.0-10.11$ & 4 & 16 & & Males & 5 & 20 \\
\hline & $11.0-11.11$ & 5 & 20 & Education & No Formal Schooling & 1 & 4 \\
\hline & $12.0-12.11$ & 6 & 24 & & Primary School & 2 & 8 \\
\hline Gender & Females & 10 & 40 & & High School & 19 & 76 \\
\hline & Males & 15 & 60 & & Technical College & 3 & 12 \\
\hline Time out of school & $>I$ month & 16 & 64 & Employment & Not employed & 14 & 56 \\
\hline & I month & 3 & 12 & & Employed & 6 & 24 \\
\hline & 4 to 14 months & 6 & 24 & & Self-employed & 4 & 16 \\
\hline & & & & & (n) & & $\%)$ \\
\hline Race & Black African & & & & 22 & & 35 \\
\hline & White & & & & 1 & & 4 \\
\hline & Indian & & & & 1 & & 4 \\
\hline & Coloured & & & & 1 & & 00 \\
\hline
\end{tabular}

PedsQL ${ }^{T M}$ these levels were created to facilitate greater clinical utility for understanding HRQoL on the PedsQL ${ }^{T M}$ modules, with the low functioning indicating issues in the lower $30-33 \%$ of the participants while the high functioning included scores of the upper $30-33 \%$. The intermediate functioning scores included children in the middle $30-33 \%{ }^{44}$.

\section{Research procedure}

All children who met the inclusion criteria and their parents were invited to participate in the study. Parent participants were requested to complete a demographic questionnaire developed by the researcher. The child participant's medical history and diagnosis were obtained from the medical record.

Data from the child participants were collected by the researcher in structured interviews. Parents completed the self-report proxy forms. If they required assistance, an occupational therapy colleague, who was the research assistant, was available to answer any questions about completion of the forms. The reliability of the data collection was ensured since the research assistant guided parents in completing the forms and all interviews with the children were completed by the researcher in a quiet room adjoining their ward. The duration of interviews was 50 minutes and 3-minute breaks provided as needed. Data were checked for completeness by the researcher. Missing data, where items were considered not applicable, were accommodated in the scoring according to the instructions for the PedsQL ${ }^{\mathrm{TM}}$ and forms were scored according to the PedsQL $L^{T M}$ manuals ${ }^{29,43}$.

\section{Data analysis}

Data were recorded on numerically coded data collection sheets to ensure anonymity. The demographic data were analysed descriptively using frequencies, percentages, and median scores. The data from the PedsQL'M Cancer Module (3.0) Generic Core Scales (4.0), using both child and parent proxy forms, were analysed using means and standard deviations so scores could be compared to norms for
PedsQL ${ }^{T M}$ HRQoL ${ }^{45}$. Non-parametric Mann Whitney $U$ tests were used to compare the data for children and parent groups, as the data were ordinal and the sample size small. TIBCO Statistica ${ }^{\mathrm{TM}} \mathrm{V}$ I 3.5 for Windows was used to analyse the data and the significance was set at the $\mathrm{p}$-value equal to or less than $0.05^{46}$.

\section{Ethical considerations}

To confirm the feasibility of the study, permission to use Peds $\mathrm{QL}^{\mathrm{TM}}$ inventory forms was first received via the MAPI Research Trust, with whom a user agreement contract was signed, and authorised by Professor J.W. Varni, the author of the PedsQL'M. The Human Research Ethics Committee of the University of Witwatersrand then provided ethical approval for the study (MI80766). The hospital research committee confirmed the ethical approval and gave permission for the research to be conducted on their premises.

In line with ethical principles the researcher provided an information sheet to all participants. The information sheet was explained in Tshwane and isiSwati, which are languages spoken by participants. They were informed that participation was voluntary, and they could withdraw from the study at any point without consequence. Parent participants provided signed informed consent for themselves and their children and the children provided signed informed assent.

\section{RESULTS}

\section{Demographic information of parent and child participants}

Only 26 children met the inclusion criteria and were interviewed. None of the children and parents who were approached refused to participate in the research. However, one parent participant did not answer more than $50 \%$ of the questions and was excluded from the study. The total sample was 25 . Table I above shows participant demographics. Most child participants were aged 8 to 8 . II months and $60 \%$ were males. Fourteen $(56 \%)$ of the parents were unemployed with a mean age of 39 years (range from 26-43 
Table II. Comparison of the differences between the Child and Parent participants on the PedsQLTM Generic Core Scales (4.0) $(n=25)$

\begin{tabular}{|c|c|c|c|c|c|c|}
\hline \multirow[b]{2}{*}{$\begin{array}{l}\text { PedsQL }{ }^{\text {TM }} \text { Generic Core } \\
\text { Scales Domains }\end{array}$} & \multicolumn{2}{|c|}{$\begin{array}{l}\text { HRQoL scores for } \\
\text { Children }\end{array}$} & \multicolumn{2}{|c|}{ HRQoL scores for Parents } & \multicolumn{2}{|c|}{$\begin{array}{l}\text { Difference between } \\
\text { HRQoL scores of children } \\
\text { and parents }\end{array}$} \\
\hline & Mean & SD & Mean & SD & p value & $\begin{array}{l}\text { Effect size } \\
\text { Cohen's d }\end{array}$ \\
\hline $\begin{array}{l}\text { Physical Functioning } \\
\text { Health summary scores }\end{array}$ & 73.37 & 24.67 & 58.20 & 29.07 & 0.068 & 0.61 \\
\hline Emotional functioning & 67.60 & 24.87 & 65.40 & 26.03 & 0.825 & 0.09 \\
\hline Social functioning & 71.80 & 25.89 & 78.12 & 23.49 & 0.466 & -0.24 \\
\hline Schooling & 66.84 & 21.22 & 62.50 & 26.91 & 0.670 & 0.20 \\
\hline $\begin{array}{l}\text { Psychosocial } \\
\text { Functioning Health } \\
\text { summary scores } \\
\text { (emotional, social, } \\
\text { and school scores } \\
\text { combined) }\end{array}$ & 63.40 & 24.01 & 60.93 & 26.53 & 0.793 & 0.10 \\
\hline Total Scale Score & 69.69 & 20.23 & 64.13 & 21.48 & 0.347 & 0.27 \\
\hline \multicolumn{5}{|l|}{ Significance at $p \leq 0.05^{*}$} & Cohen's d & 0.8 large \\
\hline \multirow{2}{*}{\multicolumn{6}{|c|}{ Significance at $\mathrm{p} \leq 0.0 \mathrm{I}^{*} *$ }} & 0.5 medium \\
\hline & & & & & & 0.2 small \\
\hline
\end{tabular}

Table III: Comparison of the differences between the Child and Parent participants on the PedsQL Cancer Module TM $3.0(n=25)$

\begin{tabular}{|c|c|c|c|c|c|c|}
\hline \multirow[b]{2}{*}{ Domains } & \multicolumn{2}{|c|}{$\begin{array}{l}\text { HRQoL scores for } \\
\text { Children }\end{array}$} & \multicolumn{2}{|c|}{$\begin{array}{l}\text { HRQoL scores for } \\
\text { Parents }\end{array}$} & \multicolumn{2}{|c|}{$\begin{array}{l}\text { Difference between HRQoL } \\
\text { scores of children and parents }\end{array}$} \\
\hline & Mean & SD & Mean & SD & p-value & Effect size Cohen's d \\
\hline Pain \& Hurt & 75.00 & 25.00 & 66.14 & 28.90 & 0.282 & 0.35 \\
\hline Nausea & 74.60 & 22.16 & 62.29 & 25.66 & 0.094 & 0.56 \\
\hline Procedural Anxiety & 69.33 & 31.34 & 49.30 & 32.86 & $0.036 *$ & 0.64 \\
\hline Treatment Anxiety & 87.00 & 22.44 & 71.87 & 29.97 & $0.038^{*}$ & 0.67 \\
\hline Worry & 82.33 & 20.45 & 51.73 & 31.56 & $0.008^{*} *$ & 1.50 \\
\hline Cognitive problems & 74.40 & 23.99 & 68.33 & 24.92 & 0.340 & 0.25 \\
\hline Perceived physical appearance & 76.00 & 27.42 & 71.18 & 32.59 & 0.749 & 0.17 \\
\hline Communication & 72.00 & 22.93 & 69.44 & 29.96 & 0.959 & 0.11 \\
\hline Total Scale Score & 76.58 & 14.78 & 63.92 & 17.62 & $0.034 *$ & 0.86 \\
\hline \multirow{3}{*}{\multicolumn{6}{|c|}{$\begin{array}{lrl}\text { Significance at } p \leq 0.05^{*} & \text { Cohen's } d \\
\text { Significance at } p \leq 0.0 I^{*} * & \end{array}$}} & 0.8 large \\
\hline & & & & & & 0.5 medium \\
\hline & & & & & & 0.2 small \\
\hline
\end{tabular}

years) and $80 \%$ were females.

Children were diagnosed with different cancers; $56 \%(n=14)$ had leukaemia's, $12 \%(n=3)$ had rhabdomyosarcomas with $8 \%$ $(n=2)$ having lymphomas and $8 \%(n=2)$ solid tumours. One child had a neuroblastoma $4 \%(n=I)$, one child had brain cancer $4 \%$ $(n=I)$, one child had osteosarcoma $4 \%(n=I)$ and one child had hematologic cancer $4 \%(n=I)$.

\section{The PedsQLTM 4.0 Generic Core Scale}

On the PedsQL ${ }^{T M}$ Generic Core Scales (4.0) the HRQoL scores for both child and parent participants fell between $6 \mathrm{I}$ to 80 indicating an intermediate level of functioning for all domains ${ }^{44}$. Table II (above) shows the comparison. Except for Social Functioning, children reported better HRQoL for all domains than their parents.
A medium effect size (0.6I) for the Physical functioning and Health (including mobility, washing, chores and energy levels) indicated that child participants considered their HRQoL as less affected than did their parents. The scores for the child and parent participants were similar for Emotional functioning which considered fear, low mood and sleep ${ }^{42}$. For Social functioning, the parent participants had a higher score than that of the child participants since the children indicated they perceived lower functioning and more occupational disruption for aspects such as relationships and play (included in the social domain). Only 18 parent and 19 child participants who had had school contact within the last 30 days (as indicated on the questionnaire) answered the questions on the Schooling domain. Although the scores for parent and child participants were similar for Schooling the child participants perceived the occupational 
disruption and role loss in this section, as having a smaller impact on their HRQoL.

On the Generic Core Scales (4.0) the composite score for psychosocial health (which was made up of the Social and Emotional functioning and Schooling domain scores) were slightly higher for the child participants. Both the children and the parents scored intermediate functioning related to HRQoL close to the low end of the intermediate range at 63 and $6 \mathrm{I}$, respectively. The total score for children and parents fell below the cut-off scores suggested by Varni et al. ${ }^{45}$ indicating these children are at risk for HRQoL deficits. Although the scores of the child and parent participants differed, no statistically significant difference was found between the two groups for any of these domains.

\section{PedsQL TM Cancer Module (3.0)}

The PedsQL ${ }^{\mathrm{TM}}$ Cancer Module ${ }^{\mathrm{TM}}$ (3.0) child repot and parent proxy reported how the child participants and parent participants perceived the cancer treatment and side-effects impacted the children's HRQoL. Table III (page 48) shows this comparison. All the HRQoL scores fell between 61 to 80 indicating intermediate functioning for all domains, with the exception of the Procedural anxiety and Worry scores, where the parents' scores below 6I, indicated low functioning ${ }^{44}$. On the PedsQL Cancer Module ${ }^{\mathrm{TM}}$, parent participants viewed the Pain and hurt domain and Nausea domain as affecting their child's HRQoL more than the children did, with large and medium effect sizes indicating a clinically important difference. For Procedural anxiety, the child participants had a statistically significantly higher mean score with a medium effect size, indicating that child participants scored themselves as functioning at an intermediate level. This domain was scored the lowest by parents. Concern about procedures including taking blood using needles was scored with the mean score was below 60 by the parent participants, who perceived the children as functioning at lower level in relation to HRQoL. A similar result was found for the Treatment anxiety domain, based on the anxiety of receiving treatment in hospital from doctors, with child participants indicating this domain did not affect their functioning. Parent participants however, perceived their children as functioning within the intermediate level of HRQoL for this domain.

Parent participants' Worry scores were also statistically significantly lower than those of the child participants who indicated that worry about their future, relapses and the effects of the treatment did not impact their functioning. The parents scored the child participants' level of functioning in relation to Worry as low, while the child participants again indicated that Worry did not impact their functioning in relation to their HRQoL. For Cognitive problems, related to memory, attention, and ability to learn, perceived physical appearance, parent and child participants had similar scores within the intermediate level of functioning related to HRQoL. A similar result was found for Communication which considered difficulty interacting with health care professionals as well as with telling others about the illness.

In Table III (page 48), the Mann Whitney $U$ test indicated parent participants had a statistically significantly $(p=0.034)$ lower total mean score (63.92) than the child participants (76.58). The large effect size indicated a clinical difference with parent participants perceiving a lower overall total HRQoL for their children.

\section{DISCUSSION}

There was a higher percentage of male child participants in this study, in accordance with international statistics suggesting that cancer occurs more commonly in boys than girls with a ratio of six males to five females ${ }^{20}$. In this study Leukaemia was the most common cancer types reported, which is in line with the American Childhood Cancer Organization (ACCO) and other studies in subSaharan Africa ${ }^{3,20}$.

Cancer is a predictor of participation restriction when it occurs at any age. Possible impairment in physical functioning accompanied by impairment in both emotional and social functioning, has been reported to predict and result in persistent dysfunction more than two years after remission, with some deficits still evident in adulthood $^{47}$. Therefore, it was important to establish the HRQoL and level of functioning in children receiving treatment for cancer from their perspective as well as that of their parents so that appropriate goals of treatment can be met.

The HRQoL related to participation of the child participants should be considered from the perspective of the children and their parents and cognisance must be taken of this cross-informant variance between the children and parents. It is important to assess both perspectives if possible. Although Sliver and Gilchrist ${ }^{14}$ suggest that occupational therapists provide intervention for muscle strengthening, range of motion, endurance and activity tolerance, these deficits were of more concern in terms of their impact on HRQoL to the parents than the children. Parent participants reported their children were less capable of participating in physical activity due to fatigue, weakness, and pain, possibly since these were the most concerning effects of cancer that they could observe. The lower level of physical functioning reported by parent participants in the current study for children in South Africa was supported in studies for hospitalised children being treated for cancer in Serbia and Taiwan. The parents of these children also had lower scores on all eight questions in the physical domain of the PedsQL ${ }^{T M}$ Generic Core Scale than the children themselves ${ }^{48,49}$.

The overall Psychosocial health of the child participants on the PedsQL ${ }^{T M}$ Generic Core Scales, calculated from the combined scores of the Emotional, Social and Schooling domains was the lowest of all scores other than physical health reported by parents. The child participants reported lower scores for Psychosocial functioning than for their Physical functioning, suggesting that they perceived themselves to be more at risk for impaired HRQoL in this domain ${ }^{43}$. Emotional functioning assessed was related to depression, anxiety, frustration, and hopelessness, which may have been influenced by a perceived decreased self-efficacy associated with a loss of autonomy and imposed treatment regimes. This is due to restrictions on their occupational performance when hospitalised, which can have serious health consequences resulting in a loss of the sense of efficacy and difficulty in adapting. Low self-efficacy, associated with low motivation ${ }^{50}$ is a key contributing factor which must be considered by occupational therapists when addressing emotional deficits in children with cancer ${ }^{14}$.

Social functioning was the only component where child participants perceived themselves to be lower functioning and more occupationally disrupted than their parents. Strain on social functioning within HRQoL is influenced by social relationships and social support available and the results of this study reflected a higher parental overprotection and perceived child helplessness - commonly seen when a child is $\mathrm{ill}^{23,51}$. It is possible that in the current study parents also did not anticipate the difficulty children experienced in being away from existing friends and peer social support networks ${ }^{43}$. This may be due to the importance of children in the middle childhood age band participating in activities that require understanding the view of another person and sharing interpersonal relationships with 
peers ${ }^{52,53}$. The ability to maintain friendships and social interactions which resulted in disruption of social activities as reported by child participants in this study, was supported by a study in Pakistan where children with cancer also reported that decreased social functioning had the greatest impact on their HRQoL ${ }^{54}$. Social functioning may have to be facilitated by the occupational therapist in the South African context, since the children have to make friends and play in a strange environment with other children from different cultures who speak different languages.

Out-of-school duration for all children ranged from 0 to 14 months, although most (64\%) had been out of school for less than a month and had been in contact with the school in the past 30 days. Child and parent participants reported the lowest means for the Schooling domain, since children had been in the acute ill during induction phase of treatment and unable to participate in formal education activities. They perceived missing school and their loss of role enactment as a scholar as their greatest occupational disruption. Speyer et al..$^{55}$ identified different hospitalisation-related stressors such as the unfamiliar environment and lack of activities associated with occupational deprivation, as contributing to difficulties in the psychological characteristics of HRQoL. It is suggested that occupational therapy therefore be provided in environments outside the ward $^{14}$. Children were also provided with age-appropriate activities to keep in their rooms. During this experience, most sessions incorporated play, leisure, and/or self-care tasks. Internally motivating activities were chosen to improve participation in sessions ${ }^{14}$. The use of occupational therapy group work outside the ward can support interaction between the children, which addresses social functioning in relation to feeling isolated and not having time or energy for social interaction ${ }^{23}$.

Arboleda and Vazquez ${ }^{56}$ emphasised that children with cancer and their parents also need to deal with mental and physical exhaustion, fear, and the many side-effects of treatment. The child and parent participants perceived the children were functioning at an intermediate level. Parents placed significantly more importance on the effect of cancer and its treatment on their child's overall HRQoL compared to the children in relation to Procedural and Treatment anxiety as well as worry. The findings of this study in the South African context had similarities to other studies where the difference in perception of the effect of physical function and procedural and treatment anxiety on the child's HRQoL ${ }^{39,48}$. The correlation between children and their parents ranged from 0.26 - 0.85 in Brazilian families on the PedsQL ${ }^{\mathrm{TM}}$ Cancer module confirming some discordant perceptions ${ }^{39}$.

This difference has been attributed to parents basing their report of HRQoL on observation of the child and procedures they undergo and not on the experience of these as reported by the children. These differences may also be due to the parents, greater understanding of the implications of the long-term consequences of cancer. Some studies have reported that older children with a diagnosis of cancer had similar scores for HRQoL, to their parents, particularly in terms of illness-related Worry and Treatment anxiety ${ }^{39,57}$. The findings in this study may therefore have been influenced by a higher number of child participants being in a younger age band of 8 years to 8 years II months' age. The findings of the current study were however similar to those PedsQL ${ }^{\mathrm{TM}}$ Cancer Module in $\mathrm{Japan}^{37}$ and China ${ }^{47}$ where children between 8 and $\mathrm{I} 2$ years reported their HRQoL was impacted more by cognitive and communication factors after procedural anxiety since these factors interfered with schoolwork and social activities.

Children with chronic health conditions ( $\mathrm{CHCs}$ ) learn how to manage their conditions through everyday life experiences with their families, peers, health providers, and others in their communities $^{58}$. Although the family remains the main source of information, the parents' lower scores may be related to a finding from Eiser, Eiser and Stride ${ }^{25}$ who reported that mothers who rate their own QOL as low, also rated the HRQoL of their child with cancer as lower than the children rated it. This suggests the mothers' own feelings about their life colour their perception of their childrens' HRQoL.

It would appear from the results of this study that during the hospitalisation phase of treatment the children with cancer were at risk for impairment in HRQoL and need support for pain and hurt, treatment anxiety, communication, and perceived physical appearance. Mohammadi, Mehraban and Damavandi ${ }^{23}$ reported that play-based occupational therapy in a playroom environment was effective in reducing anxiety in children hospitalised for cancer treatment. This supported the achievement of goals related to improvement of participation in activities and finally HRQoL.

\section{LIMITATIONS}

One of the limitations of this study was that the researcher only had six months in which to collect data. A small sample was available for the study, and therefore results of the study cannot be generalised to the South African population. The smaller than expected number of participants recruited to the study was due the high number of deaths which occurred in the oncology unit in the study period and a change in the ages of children newly admitted to the unit. The ages of the newly admitted patient were either below 5 years or teenagers, which was out of the age range for inclusion in the study.

Levels of HRQoL functioning was based of scores suggested by Beverung, Varni and Panepinto ${ }^{44}$ based on the Pain and Hurt and Pain Impact scales from the PedsQL ${ }^{\mathrm{TM}}$ Sickle Cell Disease and these scores were not confirmed for the PedsQL ${ }^{\mathrm{TM}}$ Cancer Module (3.0) used in this study.

\section{RECOMMENDATIONS}

The results of this study indicate the impact of occupational disruption on HRQoL in children hospitalised for cancer management and their parents/carers who accompany them. Although several factors including dealing with the initial diagnosis of cancer and other environmental issues may also play a role, the intermediate level of functioning impacting the HRQoL of the children indicate the need for intervention. With regards to clinical practice, it is recommended that occupational therapists facilitate the engagement and participation in meaningful occupations for these children to improve their HRQoL. Intervention, as suggested by Speyer et al.(20I0) should be considered to include adapting activities while hospitalised, intervention outside of the ward environment as well as preparation for return to previous occupations on discharge. Intervention should include socialisation and school roles for children, while addressing the effects of and anxiety related to treatment. A multidisciplinary approach to HRQoL is required with inter-professional referral for individual issues. Further research is recommended in terms of outcomes related to HRQoL and evaluation of occupational therapy intervention programmes.

\section{CONCLUSION}

The findings of the study indicated that children aged 8- 12 years admitted for long term inpatient management of cancer to a tertiary hospital experience occupation disruption that results in a HRQoL at an intermediate level of functioning, with risk of impairment in 
several domains. The child participants in the current study indicated the loss of their educational role and decreased social functioning impacted the most on their HRQoL, while their parents perceived the children's physical functioning as having a larger impact.

Scores on the Cancer Module (3.0) indicated child participants scored their HRQoL at an intermediate or high level. This differed significantly from the parent's perspective as they felt procedural treatment anxiety and worry impaired the child's HRQoL the most. The study provides evidence on the perceived HRQoL of children hospitalised for cancer treatment and their parents to guide occupational therapy intervention.

\section{ROLE OF AUTHORS}

*S'thembiso C Tembe is a postgraduate student at the University of the Witwatersrand (Wits). He conceptualised and operationalised the research. He was also responsible for data curation, analysis, and management. The writing of the initial article and subsequent drafts and is the corresponding author.

Lyndsay Koch, the lead supervisor, was involved with the conceptualisation of the research. She was responsible for reviewing and editing of the article.

Denise Franzsen, co- supervisor, was involved with the data analysis and synthesis of results, reviewing, and editing of the article.

Pat de Witt, was involved with the conceptualisation, reviewing, and editing of the article.

\section{REFERENCES}

I. Steliarova-Foucher E, Colombet M, Ries LAG, Moreno F, Dolya A, Bray F, et al. International incidence of childhood cancer, 200 I-10: a population-based registry study. The Lancet Oncology. 2017; 18(6): 7|9-731. https://doi.org/10.1016/S1470-2045(I7)30186-9

2. Stefan D, Stones D, Wainwright R, Kruger M, Davidson A, Poole J, et al. Childhood cancer incidence in South Africa, 1987-2007. South African Medical Journal. 20I5; I05(I I): 939-947. https://doi.org/ http://dx.doi.org/10.7196/SAMJ.20I5.VI05III.9780

3. The Cancer Association of South Africa. Warning Signs - Childhood Cancers. The Cancer Association of South Africa. Avaiable at: https://www.cansa.org.za/warning-signs-childhood-cancers/ (accessed 24.3.2020)

4. Miralles PM, Ramón NC, Valero SA. Adolescents with Cancer and Occupational Deprivation in Hospital Settings: A Qualitative Study. Hong Kong Journal of Occupational Therapy. 2016;27(I): 26-34. https://doi.org/10.1016/j.hkjot.2016.05.00I

5. Fakhry H, Goldenberg M, Sayer G, Aye SS, Bagot K, Pi S, et al. Health-Related Quality of Life in Childhood Cancer. Journal of Developmental \& Behavioral Pediatrics. 2013;34(6): 419-440. https:// doi.org/10.1097/DBP.0b013e31828c5fa6

6. Kasven-Gonzalez N, Souverain R, Miale S. Improving quality of life through rehabilitation in palliative care: Case report. Palliative and Supportive Care. 2010;8(3): 359-369. https://doi.org/10.1017/ S1478951510000167

7. Wallis A, Meredith P, Stanley M. Cancer care and occupational therapy: A scoping review. Australian Occupational Therapy Journal. 2020;67(2): I72-194. https://doi.org/I0.1 I I I/1440-1630.12633

8. Sleight $A$, Duker $U$. Toward a broader role for occupational therapy in supportive oncology care. American Journal of Occupational Therapy. 2016;70(4): 7004360030 pl-6. https://ajot.aota.org/ article.aspx?articleid $=252353 \mathrm{I}$.

https://dx.doi.org/10.50I4/Fajot.2016.018101

9. Hwang EJ, Lokietz NC, Lozano RL, Parke MA. Functional deficits and quality of life among cancer survivors: Implications for occupational therapy in cancer survivorship care. American Journal of Occupational Therapy. 2015;69(6): 69062900 I0pI-69062900 I0p9. https://doi.org/10.5014/ajot.2015.015974

10. American Occupational Therapy Association. Occupational Therapy Practice Framework: Domain \& Process (3rd ed). Occupational Therapy Practice Framework: Domain \& Process. 2014,68,(Suppl. I): SI-S48. https://doi.org/http://dx.doi.org/10.50I4/ajot.2014.682006

I I. Af Sandeberg M, Johansson E, Björk O, Wettergren L. Health-related quality of life relates to school attendance in children on treatment for cancer. Journal of Pediatric Oncology Nursing. 2008;25(5): 265-274. https://doi.org/10.1 I77//04345420832III9

12. Pergolotti M, Williams GR, Campbell C, Munoz LA, Muss HB. Occupational Therapy for Adults With Cancer: Why It Matters. The Oncologist. 2016;2I(3): 314-319. https://doi.org/10.1634/theoncologist.20I5-0335

13. Lyons KD, Svensborn IA, Kornblith AB, Hegel MT. A content analysis of functional recovery strategies of breast cancer survivors. OTJR Occupation, Participation and Health. 2015;35(2): 73-80. https://doi.org/10.1 177/1539449214567306

14. Silver JK, Gilchrist LS. Cancer Rehabilitation with a Focus on Evidence-Based Outpatient Physical and Occupational Therapy Interventions. American Journal of Physical Medicine \& Rehabilitation. 20I I;90(Suppl I): S5-SI5. https://doi.org/10.1097/PHM.0b013e31820be4ae

15. World Health Organisation. Children and cancer. Children's health and the environment. Avaiable at: http://www.who.int/ceh/capacity/cancer.pdf (accessed 4.5.2020)

16. Stones D, De Bruin GP, Esterhuizen TM, Stefan. DC. Childhood cancer survival rates in two South African units. South African Medical Journal. 20I4; 104(7): 50I-504.

17. Miller KD, Siegel RL, Lin CC, Mariotto AB, Kramer JL, Rowland $\mathrm{JH}$, et al. Cancer treatment and survivorship statistics, 2016. CA: A Cancer Journal for Clinicians. 2016;66(4): 27I-289. https://doi.org/10.3322/caac.21349

18. Hinds P. ' How bad is it?': the role of nursing research in prognostication. Cancer Nursing. 2010;33(2): 83-84. https://europepmc.org/abstract/med/20173428

19. Zhao Y, Brettle A, Qiu L. The effectiveness of shared care in cancesurvivors-a systematic review. International Journal of Integrated Care. 2018; 18(4). https://doi.org/10.5334/ijic.3954

20. American Cancer Society. Treating Children with Cancer. Avaiable at: https://www.cancer.org/cancer/cancer-in-children/how-arechildhood-cancers-treated.html (accessed 24.4.2020)

21. Hewitt M, Weiner SL, Simone J V., Institute of Medicine (US) and National Research Coulnstitute of Medicine (US) and National Research Council (US) National Cancer Policy Board. The Trajectory of Childhood Cancer Care. National Academies Press (US); 2003.

22. Edwards LB, Greeff LE. A descriptive qualitative study of childhood cancer challenges in South Africa: Thematic analysis of 68 photovoice contributions. SA Journal of Oncology. 2017; I(I): I-7. https://doi.org/https://dx.doi.org/10.4102/sajo.vli0.14

23. Mohammadi A, Mehraban A, Damavandi S. Effect of play-based occupational therapy on symptoms of hospitalized children with cancer: A single-subject study. Asia Pacific Journal of Oncology Nursing, 4(2), p. 168. 2017;4(2): I68-172.

24. Whiteford G. Occupational Deprivation: Global Challenge in the New Millennium. British Journal of Occupational Therapy. 2000;63(5): 200-204. https://doi.org//0.1 I77/030802260006300503

25. Eiser C, Eiser JR, Stride CB. Quality of life in children newly diag- 
nosed with cancer and their mothers. Health and Quality of Life Outcomes. 2005;3(I): I-5..

https://doi.org/10.1 186/1477-7525-3-29

26. Centers for Disease Control and Prevention. Measuring Healthy Days: Population assessment of health-related quality of life. CDC: Atlanta, Georgia. Avaiable at:

https://www.cdc.gov/hrqol/pdfs/mhd.pdf (accessed 7.3.2020)

27. Ronen GM. Reflections on the usefulness of the term 'health-related quality of life'. Developmental Medicine \& Child Neurology. Blackwell Publishing Ltd; 2017;59(I I): I I05-I I06.

https://doi.org//0.1 I I I/dmcn. 13575

28. Spilker B, Revicki D. Taxonomy of quality of life. In: , editor. . 2nd ed. , : In: Spilker B (ed.) Quality of Life and Pharmacoeconomics in Cinical Trials. 2nd ed. Philadelphia: Lippincott-Raven; 1996. p. 25-3I.

29. Varni JW, Burwinkle TM, Katz ER, Meeske K, Dickinson P. The PedSQLTM in pediatric cancer: Reliability and validity of the Pediatric Quality of Life InventoryTM Generic Core Scales, Multidimensional Fatigue Scale, and Cancer Module. Cancer. 2002;94(7): 2090-2 106. https://doi.org/10.1002/cncr. 10428

30. Russell KMW, Hudson M, Long A, Phipps S. Assessment of healthrelated quality of life in children with cancer: Consistency and agreement between parent and child reports. Cancer. 2006;106(10): 2267-2274. https://doi.org/10.1002/cncr.21871

3I. Levi RB, Drotar D. Health-related quality of life in childhood cancer: Discrepancy in parent-child reports. International Journal of Cancer. 1999;(Supplement 12): 58-64.

https://doi.org/ 10.1002/(sici) 1097-02 I5(1999)83:12+<58::aidijcl I > 3.0.co;2-a

32. Sung L, Yanofsky R, Klaassen RJ, Dix D, Pritchard S, Winick N, et al. Quality of life during active treatment for pediatric acute lymphoblastic leukemia. International Journal of Cancer. 201 I; I28(5): 1213-1220. https://doi.org/10.1002/ijc.25433

33. Longpré $\mathrm{S}$, Newman $\mathrm{R}$. The role of occupational therapy in oncology. American Occupational Therapy Association, Bethesda; 2011.

34. Warner JT. Body composition, exercise and energy expenditure in survivors of acute lymphoblastic leukaemia. Pediatric Blood and Cancer. 2008;50(S2): 456-46I. https://doi.org/I0.1002/pbc.2 I4I I

35. Hutchinson AD, Pfeiffer SM, Wilson C. Cancer-related cognitive impairment in children. Current Opinion in Supportive and Palliative Care. 20I7. II(I):70-75..

https://doi.org/10.1097/SPC.0000000000000258

36. Blatný M, Jelínek M, Sobotková V, Kepák T. The Influence of Developmental Stage on the Relationship Between Severity of Late Effects of Anticancer Therapy and Perceived Quality of Life of Childhood Cancer Survivors. 2013;16;3(3): 2 I582440 I3500678.

https://doi.org/I0.1 I77/2I582440I3500678

37. Moore JB, Beckwitt AE. Self-care operations and nursing interventions for children with cancer and their parents. Nursing Science Quarterly. 2006;19(2): 147-153. https://doi.org//0.1 I77/0894318406286594

38. Tsuji N, Kakee N, Ishida Y, Asami K, Tabuchi K, Nakadate H, et al. Validation of the Japanese version of the Pediatric Quality of Life Inventory (PedsQL) Cancer Module. Health and Quality of Life Outcomes. 20II;9(I): 22. https://doi.org/10.II86/1477-7525-9-22

39. Scarpelli AC, Paiva SM, Pordeus IA, Ramos-Jorge ML, Varni JW, Allison PJ. Measurement properties of the Brazilian version of the Pediatric Quality of Life Inventory (PedsQLTM) cancer module scale. Health and Quality of Life Outcomes. 2008;6(I): 7-12. https://doi.org/I0.II86/1477-7525-6-7

40. Ji Y, Chen S, Li K, Xiao N, Yang X, Zheng S, et al. Measuring health- related quality of life in children with cancer living in mainland China: Feasibility, reliability and validity of the Chinese mandarin version of PedsQL 4.0 Generic Core Scales and 3.0 Cancer Module. Health and Quality of Life Outcomes. BioMed Central; 20I I;9(I): I-I3. https://doi.org/10.1 186/1477-7525-9-103

41. Creative Research Systems. Sample Size Calculator. https://www.surveysystem.com/sscalc.htm

42. Taylor R. Kielhofner's model of human occupation: theory and application. New York. Wolters Kluwer; 2017;

43. Varni JW, Limbers CA, Burwinkle TM. Parent proxy-report of their children's health-related quality of life: An analysis of I 3,878 parents' reliability and validity across age subgroups using the PedsQLTM 4.0 Generic Core Scales. Health and Quality of Life Outcomes. 2007; 5(I):2-8. https://doi.org/10.1 186/1477-7525-5-2

44. Beverung LM, Varni JW, Panepinto JA. Clinically meaningful interpretation of pediatric health-related quality of life in sickle cell disease. Journal of Pediatric Hematology/Oncology. 2015;37(2): 128-133. https://doi.org/10.1097/MPH.0000000000000I77

45. Varni JW, Burwinkle TM, Seid M. The PedsQLTM as a pediatric patient-reported outcome: Reliability and validity of the PedsQLTM measurement model in 25,000 children. Expert Review of Pharmacoeconomics and Outcomes Research. 2005. p. 705-719. https://doi.org/I0.1586/14737/67.5.6.705

46. McCrum-Gardner E. Which is the correct statistical test to use? British Journal of Oral and Maxillofacial Surgery. 2008;46(I): 38-4I. https://doi.org/10.1016/j.bjoms.2007.09.002

47. Zheng DJ, Lu X, Schore RJ, Balsamo L, Devidas M, Winick NJ, et al. Longitudinal analysis of quality-of-life outcomes in children during treatment for acute lymphoblastic leukemia: A report from the Children's Oncology Group AALL0932 trial. Cancer. 2018; 124(3): 57I-579. https://doi.org/10.1002/cncr.31085

48. Chang PC, Yeh CH. Agreement between child self-report and parent proxy-report to evaluate quality of life in children with cancer. Psycho-Oncology. 2005; 14(2): 125-134.

https://doi.org/10.1002/pon.828

49. Nedović G, Marinković D, Rapaić D, Berat S, Kozomara R. Healthrelated quality of life assessment in Serbian schoolchildren hospitalized for malignant disease. Vojnosanitetski Pregled. 2013;70(2): 195-199. https://doi.org/10.2298/VSPI302195N

50. White LL, Cohen MZ, Berger AM, Kupzyk KA, Swore-Fletcher BA, Bierman PJ. Perceived self-efficacy: A concept analysis for symptom management in patients with cancer. Clinical Journal of Oncology Nursing. 20I7;2I(6): E272-E279.

https://doi.org/10.1 188/17.CJON.E272-E279

5I. Momani TG, Hathaway DK, Mandrell BN. Factors Affecting HealthRelated Quality of Life in Children Undergoing Curative Treatment for Cancer. Journal of Pediatric Oncology Nursing. 2016;33(3): 228-240. https://doi.org/10.1 I77//043454215609585

52. Barrera M, Atenafu EG, Schulte F, Bartels U, Sung L, Janzen L, et al. Determinants of quality of life outcomes for survivors of pediatric brain tumors. Pediatric Blood \& Cancer. 2017;64(9): e2648I. https://doi.org/10.1002/pbc.2648।

53. Christiansen C, Baum CM, Bass JD, R2 Library (Online service). Occupational therapy : performance, participation, and well-being.. $4^{\text {th }}$ ed. Thorofare, Slack Incorporated; $2015.668 \mathrm{p}$.

54. Chaudhry Z, Siddiqui S. Health related quality of life assessment in Pakistani paediatric cancer patients using PedsQLTM 4.0 generic core scale and PedsQLTM cancer module. Health and Quality of Life Outcomes. 2012;10(I): I-8. https://doi.org/10.1186/1477-7525-10-52

55. Speyer E, Herbinet A, Vuillemin A, Briançon S, Chastagner P. Effect 
of adapted physical activity sessions in the hospital on health-related quality of life for children with cancer: A cross-over randomized trial. Pediatric Blood \& Cancer. 2010;55(6): II60-1166.

https://doi.org//0.1002/pbc.22698

56. Arboleda J, Vazquez A. The next journey: Moving forward after cancer diagnosis and treatment. Clinical Journal of Oncology Nursing. Oncology Nursing Society; 20I7;2I (4): 4II-4I 2.

https://doi.org/I0.II88/I7.CJON.4II-4I2

57. Klassen A, Klaassen R, Pritchard S. Impact of Caring for a Child With Cancer on Parents' Health-Related Quality of Life. Journal of Clinical Oncology. 2008;26(36): 5884-5889.

https://doi.org/I0.1200/JCO.2007.15.2835

58. Beacham BL, Deatrick JA. Children with chronic conditions: Perspectives on condition management. Journal of Pediatric Nursing. 2015;30(I): 25-35. https://doi.org/10.1016/j.pedn.2014.10.01।

\section{Corresponding Author}

*S'thembiso Tembe

Email: sthe.tembe.st@gmail.com 